\title{
Long-term (10-year) efficacy of finasteride in 523 Japanese men with androgenetic alopecia
}

\author{
Masayuki Yanagisawa ${ }^{1-3}$, Hiroshi Fujimaki ${ }^{2,4}$, Akira Takeda ${ }^{1,2}$, Mitsuru Nemoto ${ }^{1}$, Takayuki Sugimoto ${ }^{1}$ and Akio Sato ${ }^{1-3 *}$ \\ ${ }^{1}$ Department of Plastic and Aesthetic Surgery, Kitasato University School of Medicine, 1-15-1 Kitasato, Minami-ku, Sagamihara, Kanagawa 252-0374, Japan \\ ${ }^{2}$ Tokyo Memorial Clinic, 2F Yamaha Building, 2-16-7 Yoyogi, Shibuya-ku, Tokyo 151-0053, Japan \\ ${ }^{3}$ Department of Plastic and Reconstructive Surgery, School of Medicine, Keio University, 35 Shinanomachi, Shinjuku-ku, Tokyo 160-8582, Japan \\ ${ }^{4}$ Department of Plastic and Reconstructive Surgery, Tokyo Women's Medical University, 8-1 Kawada-cyo, Shinjuku-ku, Tokyo 162-8666, Japan
}

\begin{abstract}
Finasteride is a standard medical treatment for androgenetic alopecia; however, no long-term study of up to 10 years has been performed in Japan. Therefore, we evaluated the efficacy and safety of $1 \mathrm{mg} /$ day finasteride in 532 Japanese men who were treated for androgenetic alopecia for 10 years. We performed subjective evaluations, using questionnaires administered to patients, in addition to the objective evaluation by doctors. The efficacy was assessed using the Norwood-Hamilton scale and modified global photographic assessment score, the standardized 7-point rating score using scalp photographs. For the Norwood-Hamilton classifications, stages IIa and IIv were combined as II, IIIa and IIIv were combined as III, IVa was combined as IV, and Va was combined as V. The proportions of patients with improvement (score $\geq 5$ ) and prevention of disease progression (score $\geq 4$ ) were $91.5 \%$ and $99.1 \%$, respectively. The Norwood-Hamilton classification grading improved by approximately 1 grade from $3.35 \pm 1.11$ to $2.55 \pm 1.30$ after the 10 -year treatment. The groups that showed Norwood-Hamilton: I/II/III and IV/V/VI/ VII at the first visit showed statistically significant differences in the modified global photographic assessment score at the 10-year treatment subjective evaluation $(6.27 \pm 0.62$ vs $5.52 \pm 0.78, \mathrm{P}<0.001)$. Furthermore, the quantitative analysis of the objective evaluation using the questionnaire was also significantly different $(\mathrm{P}<0.001)$. During the study period, no serious adverse reaction was recognized. Long-term $(10$-year) treatment with $1 \mathrm{mg} / \mathrm{day}$ finasteride in Japanese men with androgenetic alopecia showed high efficacy in subjective and objective evaluations.
\end{abstract}

\section{Introduction}

Finasteride was authorized in Japan for the treatment of androgenetic alopecia (AGA) in 2005; subsequently, prescription of this medication commenced. Presently, finasteride is authorized in over 60 countries and is administered to over 3 million patients for AGA. Dihydro-testosterone (DHT) has a key role in mediating progressive scalp hair loss in men with AGA, and finasteride blocks the conversion of testosterone to DHT as a selective type II $5 a$-reductase inhibitor, which justifies its use in AGA treatment [1-3]. Although the efficacy of AGA treatment with finasteride has been demonstrated by several large-scale and long-term studies, [4-7] no long-term investigation for up to 10 years has yet been conducted in Japanese subjects [8-10]. Therefore, the objective of this study was to evaluate the efficacy and safety of large-scale and long-term AGA treatment with finasteride, which, to our knowledge, is the first of such studies in Japan. In this study, a subjective evaluation was conducted using a questionnaire on AGA administered to each patient; moreover, an objective evaluation was performed by doctors.

\section{Methods}

\section{Study population}

We examined 532 Japanese men who had been diagnosed with AGA at the first visit to the Tokyo Memorial Clinic Hirayama (hereafter, "the clinic") during the period between December 2005 and January 2009 and had been treated with $1 \mathrm{mg} /$ day finasteride for 10 years until January 2019. Furthermore, all patients answered a questionnaire about the long-term treatment of AGA after 10 years treatment. Written informed consent for participation in the present study was obtained from all patients.

\section{Efficacy Evaluation}

\section{Objective efficacy - Scalp photographs}

The efficacy was objectively assessed using the NorwoodHamilton scale $(\mathrm{N}-\mathrm{H})[11,12]$ and the modified global photographic assessment score (MGPA) [13,14], (Figure 1) with the following standardized 7-point rating score using scalp photographs: 1, significant disease progression; 2 , moderate disease progression; 3 , slight disease progression; 4, no change; 5 , slight improvement; 6 , moderate improvement; and 7, significant improvement. In the N-H classifications, stages IIa and IIv were combined as stage II, IIIa and IIIv were combined as III, IVa was combined as IV, and Va was combined as V. In the MGPA assessment, we evaluated scalp photographs at the first visit and yearly and categorized the MGPA in every N-H classification at the first visit (Figure 2).

\section{Subjective efficacy - Questionnaire}

The subjective efficacy was assessed using a long-term AGA treatment questionnaire, which was digitalized to the following numerical rating scale (NRS: 0-3: slightly, 4-6: moderate, 7-10:

${ }^{\star}$ Correspondence to: Akio Sato, MD, $\mathrm{PhD}$. Tokyo Memorial Clinic, 2F Yamaha Building, 2-16-7 Yoyogi, Shibuya-ku, Tokyo 151-0053, Japan, E-mail: drsato@ crux.ocn.ne.jp

Key words: androgenetic alopecia, finasteride, Japanese, long-term, modified global photographic assessment, Norwood-Hamilton scale

Received: September 09, 2019; Accepted: September 16, 2019; Published: September 19, 2019 
significant) [15,16] (Figure 3). Questionnaire items were as follows. Q1: To what degree are you satisfied with your treatment? Q2: To what degree do you feel your hair has improved? Q3: To what degree do you wish to continue treatment? Q4: How would you compare your hair loss to the hair of people of the same age pre-treatment? Q5: How would you compare your hair loss to the hair of people of the same age 10 years post-treatment? Numerical variables of the results are presented as summary statistics (mean \pm standard deviation); the data were analyzed using Welch's t-test for the efficacy evaluation. Statistical analyses were performed using Microsoft Excel Statistics program version 2.14 ; a $\mathrm{P}<0.05$ was considered statistically significant.

\section{Safety Evaluation}

Adverse reactions were recorded to evaluate safety by questionnaire.
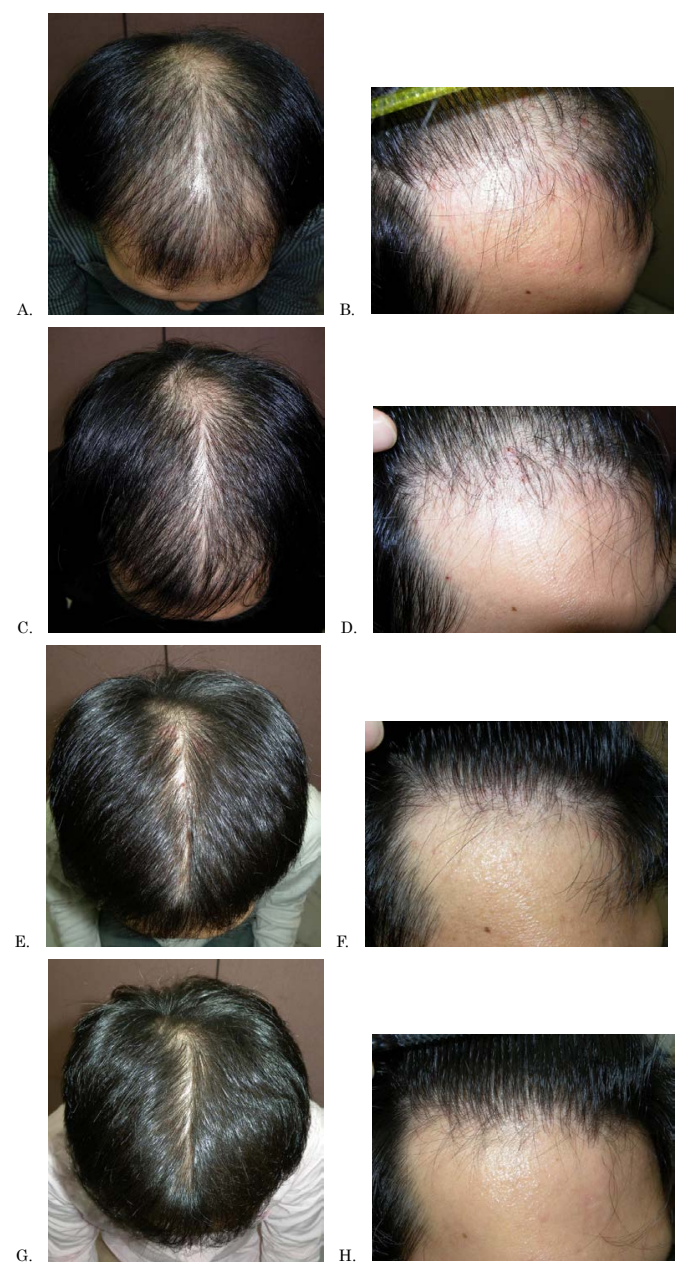

Figure 1. The modified global photographic assessment score (MGPA): the standardized 7-point rating score using scalp photographs: 1 , significant disease progression; 2 , moderate disease progression; 3 , slight disease progression; 4 , no change; 5 , slight improvement; 6 , moderate improvement; and 7 , significant improvement.

Scalp photographs of representative patient's for evaluation of MGPA.

Vertex photographs and (or) forehead photographs were taken for every patient at each examination and used for evaluation.

A: Base line $(\mathrm{MGPA}=4)$ (Vertex photograph at first visit)

$\mathrm{B}$ : Base line (MGPA=4) (Forehead photograph at first visit)

$\mathrm{C}: \mathrm{MGPA}=5$ (Vertex photograph at 6 months of treatment)

D: $M G P A=5$ (Forehead photograph at 6 months of treatment)

E: MGPA $=6$ (Vertex photograph at 24 months of treatment)

F: $M G P A=6$ (Forehead photograph at 24 months of treatment)

G: MGPA $=7$ (Vertex photograph at 60 months of treatment)

$\mathrm{H}: \mathrm{MGPA}=7$ (Forehead photograph at 60 months of treatment)

(There is no display about cases of MGPA: $1 / 2 / 3$ )
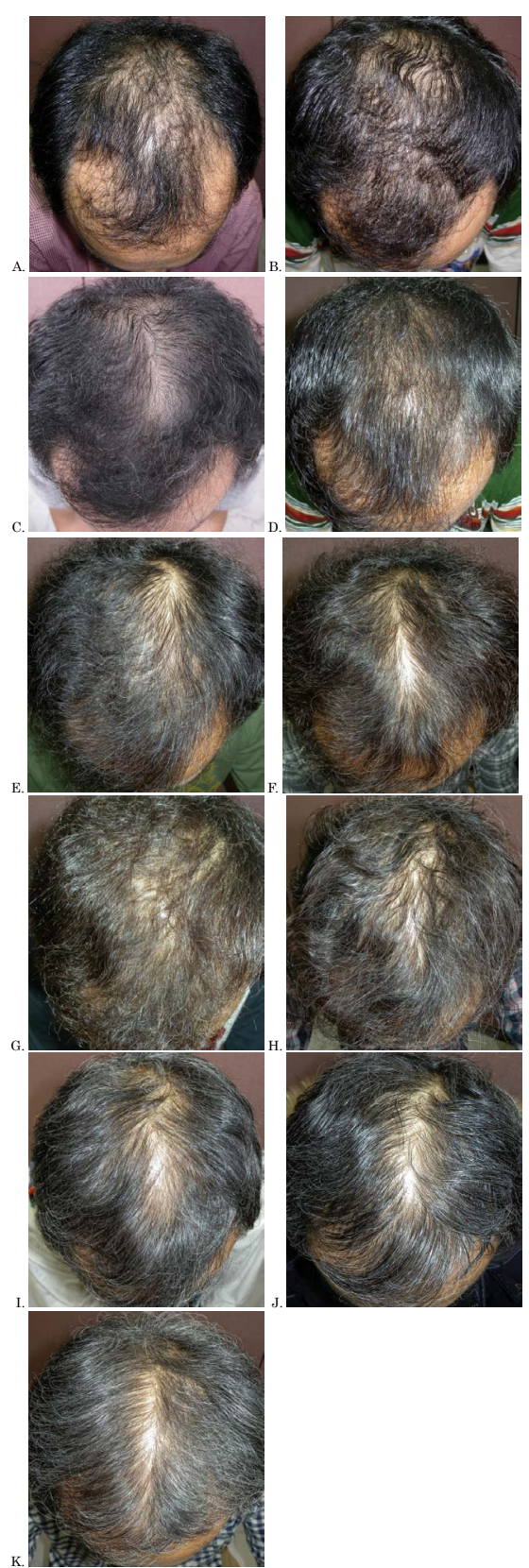

Figure 2. Scalp photographs at the first visit and yearly, were evaluated about MGPA and N-H A: At first visit

B: At 1 year of treatment

C: At 2 years of treatment

D: At 3 years of treatment

E: At 4 years of treatment

F: At 5 years of treatment

G: At 6 years of treatment

$\mathrm{H}$ : At 7 years of treatment

I: At 9 years of treatment

$\mathrm{K}$ : At 10 years of treatment

\section{Results}

\section{Patient Characteristics}

The characteristics of all patients evaluated for AGA treatment efficacy were as follows: age at first visit, $37.8 \pm 10.0$ years; age range, 20-69 years; and values of each $\mathrm{N}-\mathrm{H}$ at the first visit: I/II/III/IV/V/VI/ VII, 6/116/204/124/61/18/3, respectively. 


\section{Efficacy Evaluation in 10 years treatment}

\section{Objective efficacy - Scalp photographs}

The proportions of patients with improvement $(\mathrm{MGPA} \geq 5)$ or prevention of disease progression $(\mathrm{MGPA} \geq 4)$ at treatment year 10 were $91.5 \%$ (487/532) and $99.1 \%$ (527/532), respectively. The efficacy evaluation showed that the MGPA improved significantly from year 1 through to year 10 of treatment compared with the baseline (MGPA =4). The MGPA of each N-H group was linear according to the N-H number; the total was between N-H:III and N-H:IV (Figure 4 and Table 1). Receiver operating characteristic curve (ROC) analysis was performed to classify patients with improvement (MGPA $\geq 5)$ and deteriorating $(\mathrm{MGPA}<5)$ condition at year 10 of treatment; the cut-off point was N-H: III. (the area under the curve [AUC], which indicates the predictive value, was 0.746 .). Furthermore, the MGPA of the total study population and the N-H:I/II/III group at the first visit improved from year 5 through to year 10, with statistically significant differences $(\mathrm{P}<0.001)$. The early stage AGA group $(\mathrm{N}-\mathrm{H}: \mathrm{I} / \mathrm{II} / \mathrm{III}$ at first visit $)$ showed more improvement with long-term AGA treatment (10-year) with finasteride than the other groups did in the objective evaluation. The N-H classification of AGA patients improved by approximately 1 grade over the 10-year treatment with finasteride; significant differences were observed from pre-treatment $(3.35 \pm 1.11)$ to post-treatment $(2.55$ $\pm 1.30, \mathrm{P}<0.001)$ in comparison of digitized classification.

\section{Subjective evaluation - Questionnaire}

The high subjective efficacy of AGA treatment was revealed by the answers to Q1, "To what degree are you satisfied with your treatment?" (7.09 \pm 1.78$)$; Q2, “To what degree do you feel your hair has improved?" (6.95 \pm 1.82$)$, and Q3, “To what degree do you wish to continue treatment?" $(8.26 \pm 1.84)$.

A significant difference was observed between Q4 and Q5 (pre- and 10 -year post-treatment, $3.41 \pm 2.12$ and $4.93 \pm 2.21$, respectively, $\mathrm{P}<$ 0.001) (Table 2). Furthermore, a comparison between the N-H: I/II/ III and N-H:IV/V/VI/VII groups at first visit revealed a statistically significant difference in the answer to $\mathrm{Q} 1,2,4$, and $5(\mathrm{P}<0.001)$ and $\mathrm{Q} 3(\mathrm{P}<0.05)$. The early stage AGA group $(\mathrm{N}-\mathrm{H}: \mathrm{I} / \mathrm{II} / \mathrm{III}$ at first visit $)$ also showed a greater improvement following long-term (10-year) treatment with finasteride than the other groups did in the subjective evaluation.

\section{Safety Evaluation}

During the study period for 10 years, no serious adverse reaction was recognized. Mild and temporary adverse reactions were recorded in $6.8 \%(36532)$ of the entire study population by questionnaire. The adverse reactions were decreased libido $(5.6 \%, \mathrm{n}=30)$ and erectile dysfunction $(3.0 \%, \mathrm{n}=16)$. All adverse reactions were mild and all patients continued treatment for 10 years.

\section{Discussion}

\section{Efficacy Evaluation}

\section{Objective evaluation - Scalp photographs}

We evaluated the long-term (10-year) efficacy and safety of AGA treatment with $1 \mathrm{mg} /$ day finasteride in a large study population (532 patients), as the first study of this kind in Japan, to our knowledge. A high objective efficacy was demonstrated by the MGPA, which revealed improvement and prevention of disease progression in $99.1 \%$ of the 532 Japanese men with AGA treated with $1 \mathrm{mg}$ /day finasteride for 10 years. Furthermore, the outcome was similar to or better than that reported

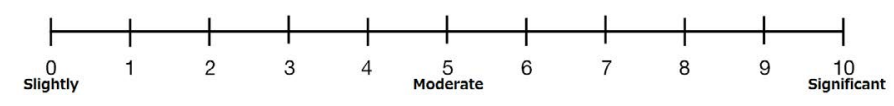

Figure 3. Numerical Rating Scale (NRS): entry example. NRS: the standardized 11-point rating was scored by patients themselves, $0-3$ : slightly, 4-6: moderate, 7-10: significant

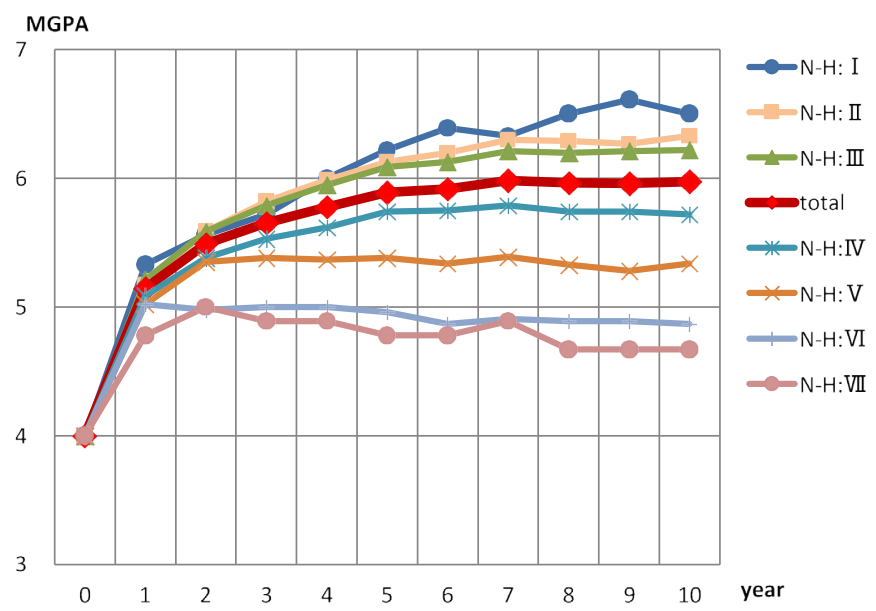

Figure 4. Changes in modified global photographic assessment scores (MGPA) from before treatment through year 10 of treatment on each Norwood-Hamilton scale $(\mathrm{N}-\mathrm{H})$ group at first visit.

Table 1. Changes in modified global photographic assessment scores (MGPA) from before treatment through to year 10 in each Norwood-Hamilton scale $(\mathrm{N}-\mathrm{H})$ group at first visit

\begin{tabular}{|c|c|c|c|c|c|c|}
\hline N-H & Number & $\mathbf{O Y}$ & $1 Y$ & $2 Y$ & $3 Y$ & $4 Y$ \\
\hline I & 6 & 4.00 & $5.33 \pm 0.51$ & $5.56 \pm 0.50$ & $5.72 \pm 0.62$ & $6.00 \pm 0.64$ \\
\hline II $(\mathbf{a}, \mathbf{v})$ & 116 & 4.00 & $5.17 \pm 0.61$ & $5.59 \pm 0.70$ & $5.82 \pm 0.72$ & $5.99 \pm 0.75$ \\
\hline III $(a, v)$ & 204 & 4.00 & $5.21 \pm 0.47$ & $5.59 \pm 0.53$ & $5.79 \pm 0.55$ & $5.95 \pm 0.56$ \\
\hline IV (a) & 124 & 4.00 & $5.09 \pm 0.42$ & $5.38 \pm 0.50$ & $5.53 \pm 0.57$ & $5.62 \pm 0.60$ \\
\hline$V(a)$ & 16 & 4.00 & $5.02 \pm 0.29$ & $5.35 \pm 0.41$ & $5.38 \pm 0.40$ & $5.37 \pm 0.46$ \\
\hline VI & 18 & 4.00 & $5.02 \pm 0.36$ & $4.98 \pm 0.38$ & $5.00 \pm 0.29$ & $5.00 \pm 0.27$ \\
\hline VII & 3 & 4.00 & $4.78 \pm 0.31$ & $5.00 \pm 0.27$ & $4.89 \pm 0.29$ & $4.89 \pm 0.42$ \\
\hline Total & 532 & 4.00 & $5.14 \pm 0.51$ & $5.49 \pm 0.59$ & $5.66 \pm 0.62$ & $5.78 \pm 0.66$ \\
\hline \multicolumn{2}{|c|}{$5 Y$} & $6 Y$ & $7 Y$ & $8 Y$ & $9 Y$ & $10 Y$ \\
\hline \multicolumn{2}{|c|}{$6.22 \pm 0.53$} & $6.39 \pm 0.53$ & $6.39 \pm 0.64$ & $6.50 \pm 0.63$ & $6.61 \pm 0.49$ & $6.50 \pm 0.57$ \\
\hline \multicolumn{2}{|c|}{$6.13 \pm 0.67$} & $6.20 \pm 0.67$ & $6.20 \pm 0.65$ & $6.29 \pm 0.67$ & $6.27 \pm 0.70$ & $6.33 \pm 0.66$ \\
\hline \multicolumn{2}{|c|}{$6.09 \pm 0.58$} & $6.13 \pm 0.58$ & $6.13 \pm 0.59$ & $6.20 \pm 0.61$ & $6.21 \pm 0.60$ & $6.22 \pm 0.59$ \\
\hline \multicolumn{2}{|c|}{$5.74 \pm 0.62$} & $5.75 \pm 0.62$ & $5.75 \pm 0.73$ & $5.74 \pm 0.73$ & $5.74 \pm 0.74$ & $5.72 \pm 0.79$ \\
\hline \multicolumn{2}{|c|}{$5.38 \pm 0.53$} & $5.34 \pm 0.53$ & $5.34 \pm 0.58$ & $5.33 \pm 0.64$ & $5.28 \pm 0.68$ & $5.34 \pm 0.61$ \\
\hline \multicolumn{2}{|c|}{$4.96 \pm 0.47$} & $4.87 \pm 0.47$ & $4.87 \pm 0.49$ & $4.89 \pm 0.58$ & $4.89 \pm 0.66$ & $4.87 \pm 0.64$ \\
\hline \multicolumn{2}{|c|}{$4.78 \pm 0.31$} & $4.78 \pm 0.31$ & $4.78 \pm 0.42$ & $4.67 \pm 0.27$ & $4.67 \pm 0.27$ & $4.67 \pm 0.27$ \\
\hline \multicolumn{2}{|c|}{$5.89 \pm 0.68$} & $5.92 \pm 0.72$ & $5.92 \pm 0.72$ & $5.96 \pm 0.77$ & $5.96 \pm 0.78$ & $5.96 \pm 0.78$ \\
\hline
\end{tabular}

Mean \pm Standard Deviation $($ Mean $\pm \mathrm{SD}) *$, there were significant differences in MGPA at year 10 between N-H:I/II/III and N-H:IV/V/VI/VII groups $(\mathrm{P}<0.001)$

Table 2. Numerical analysis of answers to questionnaire using numerical rating scale (NRS)

\begin{tabular}{|c|c|}
\hline Q1 & $7.09 \pm 1.78$ \\
\hline Q2 & $6.95 \pm 1.82$ \\
\hline Q3 & $8.26 \pm 1.84$ \\
\hline Q4 & $3.41 \pm 2.12$ \\
\hline Q5 & $4.93 \pm 2.21$ \\
\hline
\end{tabular}

Mean \pm SD *

Q1: To what degree are you satisfied with your treatment?

Q2: To what degree do you feel your hair has improved?

Q3: To what degree do you wish to continue treatment?

Q4: How would you compare your hair loss to the hair of people of the same age pre-treatment? Q5: How would you compare your hair loss to the hair of people of the same age 10 years post-treatment? 
by other studies in Japan [8-10,13,17]. Differences have been known to occur in the progression of AGA symptoms between Japanese and Caucasian men $[8,18]$. This efficacy of the investigated treatment in Japanese men exceeded that reported in other studies in Caucasians. The superior response of Japanese men with AGA was reported to likely be attributable to their hair characteristics (greater diameter, black color, and lower density), which facilitated the detection of slight changes [10,19-23]. A novel finding observed in this study was the significant difference in the improvement of AGA following finasteride treatment between the N-H: I/II/III and N-H: IV/V/VI/VII groups at the first visit. The ROC analysis revealed a similar difference, that was performed to classify patients with improvement $(M G P A \geq 5)$ and deteriorating $(\mathrm{MGPA}<5)$ condition at year 10 of treatment; the cut-off point was N-H: III (AUC: 0.746). Furthermore, the MGPA of the total study population and the $\mathrm{N}-\mathrm{H}$ : I/II/III group at the first visit significantly improved from treatment year 5 to $10(\mathrm{P}<0.001)$. This efficacy was different from that of a 5-year study in Japanese men, which reported that the efficacy began to plateau after 4 years of treatment [10]. Several studies have reported that AGA progresses in N-H classification with age, $[7,11,12,18]$ and that younger patients show more improvement than that of older patients with AGA treatment $[24,25]$. In this study, AGA patients at the early stage of $\mathrm{N}-\mathrm{H}$ classification showed more improvement than patients at the later stage did.

\section{Subjective evaluation - Questionnaire}

Several studies using questionnaires on AGA administered to patients and doctors have been reported [26-28]. We evaluated the questionnaires administered to patients with AGA who were treated with finasteride for 10 years. A highly subjective efficacy was revealed by all answers to the questionnaires. Especially, the analysis showed that the score of the response to Q3; "To what degree do you wish to continue treatment?" was high $(8.26 \pm 1.84)$, which could be attributed to the fact that the patients had undergone the treatment for 10 years already. However, the subjective efficacy of long-term treatment of AGA with finasteride was evident based on the differences in the results between Q4 and Q5 (pre- and post-treatment, $3.41 \pm 2.12$ and $4.93 \pm$ 2.21 , respectively, $\mathrm{P}<0.001$ ). A high efficacy and significant difference in improvement of AGA with finasteride treatment was also observed between the N-H: I/II/III and N-H: IV/V/VI/VII groups at first visit in the objective evaluation using the questionnaire.

\section{Safety evaluation}

Adverse reactions were recorded in $6.8 \%(36 / 532)$ in the safety evaluation in this study, which was slightly higher than that observed in other studies in Japanese men $[8,9,17]$. This observation was thought to have been caused by the fact that the investigation period of this study was longer than that of others and, therefore, the patients had aged more. Incidences of decreased libido and erectile dysfunction have been known to increase in proportion with age. In the investigation in 40 years or older of Asians, the incidences of decreased libido and erectile dysfunction were $6.0-38.7 \%$ and $40.6-70.0 \%$, respectively $[29,23]$. Overall, the adverse reactions were all mild, and the incidence was lower than the generic incidence of decreased libido and erectile dysfunction in Asians. As adverse reactions were recorded by patients in a subjective questionnaire, the result was thought to be slightly different from the correct number of adverse reactions in this study. Strict safety evaluation was not investigated in this study. Several studies on AGA treatment with finasteride have reported that there are no significant differences from the placebo in adverse reactions, $[13,30,31]$ and that the risk of discontinuing the treatment because of adverse reaction is similar to that of the placebo [32].
In summary, long-term (10-year) AGA treatment with finasteride $1 \mathrm{mg} /$ day demonstrated a high efficacy and safety based on subjective and objective evaluations in Japanese men. Specifically, the N-H classification of AGA patients improved by approximately 1 grade after 10 years of treatment with finasteride. Furthermore, a novel discovery of this study was that the group with $\mathrm{N}-\mathrm{H}: \mathrm{I} / \mathrm{II} / \mathrm{III}$ at the first visit showed greater improvement than the group with N-H: IV/V/ VI/VII at first visit, following 10 years of AGA treatment with finasteride. We recommend that AGA patients should start treatment with $1 \mathrm{mg} /$ day finasteride at the early stage of classification of AGA (within N-H: I, II, or III) for adequate efficacy.

\section{Acknowledgments}

We would like to thank the staffs and residents of our departments.

\section{Conflict of interest statement}

The authors state no conflict of interests

\section{References}

1. Kaufman KD, Dawber RP (1999) Finasteride, a Type 2 5alpha-reductase inhibitor, in the treatment of men with androgenetic alopecia. Expert Opin Investig Drugs 8: 403-415.

2. Drake L, Hordinsky M, Fiedler V (1999) The effects of finasteride on scalp skin and serum androgen levels in men with androgenetic alopecia. J Am Acad Dermatol 550-554.

3. Kaufman KD (2002) Androgens and alopecia. Mol Cell Endocrinol 198: 89-95. [Crossref]

4. Finasteride Male Pattern Hair Loss Study Group (2002) Long-term (5-year) multinational experience with finasteride $1 \mathrm{mg}$ in the treatment of men with androgenetic alopecia. Eur J Dermatol 12: 38-49. [Crossref]

5. Kaufman KD, Girman CJ, Round EM, Johnson-Levonas AO, Shah AK, et al (2008) Progression of hair loss in men with androgenetic alopecia (male pattern hair loss): long-term (5-year) controlled observational data in placebo-treated patients. Eur $J$ Dermatol 18: 407-411.

6. Kaufman KD, Rotonda J, Shah AK, Meehan AG (2008) Long-term treatment with finasteride $1 \mathrm{mg}$ decreases the likelihood of developing further visible hair loss in men with androgenetic alopecia (male pattern hair loss). Eur J Dermatol 18: 400-406.

7. Rossi A, Cantisani C, Scarno M, Trucchia A, Fortuna M, et al. (2011) Finasteride, 1 $\mathrm{mg}$ daily administration on male androgenetic alopecia in different age groups: 10-year follow-up. Dermatol Ther 24: 455-461.

8. Sato A, Takeda A (2012) Evaluation of efficacy and safety of finasteride $1 \mathrm{mg}$ in 3177 Japanese men with androgenetic alopecia. J Dermatol 39: 27-32. [Crossref]

9. Kawashima M, Mizoguchi M, Igarashi A (2006) Long term (3 years) efficacy and safety profiles of finasteride in Japanese men with AGA (androgenetic alopecia). Jpn J Clin Dermatol 60: 521-530.

10. Yoshitake T, Takeda A (2015) Five-year efficacy of finasteride in 801 Japanese men with androgenetic alopecia. J Dermatol 42: 735-738. [Crossref]

11. HAMILTON JB (1951) Patterned loss of hair in man; types and incidence. Ann NY Acad Sci 53: 708-728. [Crossref]

12. Norwood O (1975) Male pattern baldness: classification and incidence. South Med J 68: $1359-1365$.

13. Kawashima M, Hayashi N, Igarashi A, Kitahara H, Maeguchi M, et al. (2004) Finasteride in the treatment of Japanese men with male pattern hair loss. Eur $J$ Dermatol 14: 247-254. [Crossref]

14. Kaufman KD, Olsen EA, Whiting D (1998) Finasteride in the treatment of men with androgenetic alopecia. Finasteride Male Pattern Hair Loss study group. J Am Acad Dermatol 39: 578-589.

15. Farrar JT, Young JP, LaMoreaux L, Werth JL, Poole RM (2001) Clinical importance of changes in chronic pain intensity measured on an 11-point numerical pain rating scale. Pain 94: 149-58.

16. Williamson A, Hoggart B (2005) Pain: a review of three commonly used pain rating scales. J Clin Nurs 14: 798-804. [Crossref]

17. Sato A, Sanada Y, Hirayama T (2007) Clinical efficacy of Finasteride $1 \mathrm{mg}$ Among 708 Patients with AGA (Androgenetic alopecia). Skin Surgery 16: 126-131. 
18. Takashima I, Iju M, Sudo M (1981) Alopecia Androgenetica - Its incidence in Japanese and associated conditions. In: Orfanos CE, Montagna W, Stuettgen G (Eds) Hair Research: Status and Future Aspects. Berlin: Springer Verlag pp. 287-293.

19. Otsuka H, Nemoto T (1988) Study on Japanese hair. J Jpn Cosmet Sci Soc 12: 192-197.

20. Franbourg A, Hallegot P, Baltenneck F, Toutain C, Leroy F (2003) Current research on ethnic hair. J Am Acad Dermatol 48: S115-119. [Crossref]

21. Hayashi S, Okumura T, Ishida A (1976) Preliminary study on racial difference in scalp hair. In: Kobori T, Montagna W (Eds). Biology and Disease of the Hair 555-561.

22. Hori Y, Nakagawa H (1987) Hair Color and Melanin Pigments Racial differences. In: Kobori T, Montagna W (Eds) Chapter 7. The Medical Science of Hair pp. 148-172.

23. Pinkus F (1927) Die Gruppenstellung der Haare. In: Jadassohn J (Ed) Handbuck der Haut-und Geschlechtskrankheiten. B, Teil 1, Berlin, German pp. 239-244.

24. Whiting DA, Olsen EA, Savin R, Halper L, Rodgers A, et al. (2003) Efficacy and tolerability of finasteride $1 \mathrm{mg}$ in men aged 41 to 60 years with male pattern hair loss. Eur J Dermatol 13: 150-160. [Crossref]

25. Olsen EA, Whiting DA, Savin R (2012) Global photographic assessment of men aged 18 to 60 years with male pattern hair loss receiving finasteride $1 \mathrm{mg}$ or placebo. $J \mathrm{Am}$ Acad Dermatol 67: 379-386.
26. Miyakura T, Tsuboi R, Okoshi K (2008) An analysis of the classification and background of AGA patients treated with finasteride and remarks on the efficacy of this drug based on patient feedback. Jpn J Dermatol 118: 213-219.

27. Lulic Z, Inui S, Sim WY (2017) Understanding patient and physician perceptions of male androgenetic alopecia treatments in Asia-Pacific and Latin America. J Dermatol 44: 892-902.

28. Sorbellini E, Pinto D, Marzani B, Rinaldi F (2018) Drug Treatment for Androgenetic Alopecia: First Italian Questionnaire Survey on What Dermatologists Think about Finasteride. Dermatol Ther (Heidelb) 8: 259-267.

29. Low WY (2008) Erectile dysfunction, premature ejaculation and hypogonadism and men's quality of life. an Asian perspective. JMH 5: 282-288.

30. Cheng JYW (2007) Prevalence of erectile dysfunction inAsian populations: a metaanalysis. Int J Impot 19: 229-244.

31. Gupta A, Charrette A (2014) The efficacy and safety of 5a-reductase inhibitors in androgenetic alopecia: a network meta-analysis and benefit-risk assessment of finasteride and dutasteride. J Dermatolog Treat 25: 156-161.

32. Mella J, Perret MC, Manzotti M, Catalano HN, Guyatt G (2010) Efficacy and safety of finasteride therapy for androgenetic alopecia. Arch Dermatol 146: 1141-1150.

Copyright: $@ 2019$ Yanagisawa M. This is an open-access article distributed under the terms of the Creative Commons Attribution License, which permits unrestricted use, distribution, and reproduction in any medium, provided the original author and source are credited. 